\title{
Relationship between Family Interaction pattern, Family Burden and Quality of Life among Caregivers of Patients with Alcohol Dependence
}

\author{
Dr. M. Senthil ${ }^{1 *}$, Dr. Manisha Kiran ${ }^{2}$
}

\section{ABSTRACT}

Alcohol and drug use disorders have devastating physical, mental, and socio-economic consequences not only for patients but also for their families. Their illness substantially affects the quality of life of other family members, including financial security, mental health, social networks, and productivity. So the present study was an attempt to assess the relationship between family interaction pattern, family burden and Quality of life among caregivers of individuals with alcohol dependence. This study was conducted at the Ranchi Institute of NeuroPsychiatry and Allied Sciences, Ranchi. It was a cross sectional study and purposive sampling was used. The present study consisted of 60 caregivers of alcohol dependence, those who were willing to participate and those who have satisfied with inclusion and exclusion criteria have been included in the study. The socio demographic data sheet had been used for collecting socio demographic details of the caregivers of individuals with alcohol dependence. To assess the alcohol severity of the patient, the alcohol severity index scale was applied. Family interaction pattern scale, family burden interview schedule and WHO Quality of life scale were applied on the caregivers of individuals with alcohol dependence. The findings indicated that there is significant positive correlation exist between family interaction pattern, Family burden and quality of life among caregivers of individuals with alcohol dependence.

Keywords: Alcohol Dependence, Caregivers, Family Interaction Pattern, Family Burden, Quality Of Life.

Substance abuse/dependence causes significant harm to self, family and society as a whole and also it inflicts heavy cost on family and nation. These include direct and indirect cost. A drug addict spends heavy amount of money for his addiction. Furthermore, it can interfere with an

\footnotetext{
${ }^{1}$ Psychiatric Social Worker, Department of Psychiatric Social Work, National Institute of Mental Health and Neuro Sciences (NIMHANS), Bangalore

${ }^{2}$ Associate Professor \& Head, Department of Psychiatric Social Work, Ranchi Institute of Neuro-Psychiatry \& Allied Sciences (RINPAS), Kanke, Ranchi

*Responding Author

(C) 2016 I M Senthil, M Kiran; licensee IJIP. This is an Open Access Research distributed under the terms of the Creative Commons Attribution License (http://creativecommons.org/licenses/by/2.0), which permits unrestricted use, distribution, and reproduction in any Medium, provided the original work is properly cited.
} 
individual's employment and productivity (Shyangwa, 2008). Indirect losses also include losses due to premature death of abuser either due to natural course of disease, trauma or suicide. Substance abuse is associated with increased risk of other diseases such as HIV, tuberculosis and sexually transmitted diseases. These co-morbidities lead to additional burden on family (Panda, 2005). In addition to huge economical losses associated with substance abuse, there are many psychological problems faced by family members and the greatest sufferer is the woman in the family as a mother and/or as a wife of the substance abuser and the burden faced by the women is the burden of blame-blame of being responsible for the substance use, blame of hiding the issue from others and blame of not getting timely treatment. Thus the woman often became the victim of not just the substance abuser, but also society. This often led to feelings of guilt, depression (47 percent), anxiety (55 percent), isolation, frequent suicidal thoughts (35 percent), insomnia (47 percent), physical violence (43 percent) and verbal aggression (50 percent) (Shankardass, 2001). A study on psychopathology in children of fathers with substance use disorders found that preadolescent children were known to have more behaviour problems, depression, and anxiety (Clark, 1997). Caregiver burden is important in part because a caregiver who is exhausted, depressed, or physically ill may be unable to provide the quality of care needed to their care recipient. The relationship between caregiver burden, mental and physical health have been studied in great detail, the relationship between caregiver burden and alcohol use has largely been ignored. Alcohol use, particularly alcohol use that meets criteria for abuse or dependency, is a cause for concern among caregivers, as both their health and the health of their care recipient is at risk, particularly if they are responsible for assisting their care recipient with activities of daily living (Conlin, 1995 \& Cooney, 1995).

\section{METHODOLOGY}

The present study consisted of 60 caregivers of individuals with alcohol dependence. It was a cross sectional study and purposive sampling techniques was used and data collected from outpatient and inpatient department of Ranchi institute of Neuro Psychiatry and Allied Sciences (RINPAS), Ranchi. Patients were selected as per ICD -10 DCR criteria. The following tools were used such as Socio- demographic data, GHQ-12, Severity of alcohol dependence questionnaire, family interaction pattern scale, family burden interview schedule and WHO Quality of life scale. 


\section{RESULTS}

Table-1: Correlation between Family Interaction Pattern and Family burden among caregivers of individuals with Alcohol dependence

\begin{tabular}{|c|c|c|c|c|c|c|c|}
\hline & \multicolumn{6}{|c|}{ Family burden scale } \\
\hline & & $\begin{array}{l}\text { Financial } \\
\text { burden }\end{array}$ & $\begin{array}{l}\text { Disruption } \\
\text { of routine } \\
\text { family } \\
\text { Activities }\end{array}$ & $\begin{array}{l}\text { Disruption } \\
\text { of family } \\
\text { leisure }\end{array}$ & $\begin{array}{l}\text { Disruption } \\
\text { of family } \\
\text { interaction }\end{array}$ & $\begin{array}{l}\text { Effect } \\
\text { on } \\
\text { physical } \\
\text { health } \\
\text { of } \\
\text { others } \\
\end{array}$ & $\begin{array}{l}\text { Effect } \\
\text { on } \\
\text { mental } \\
\text { health } \\
\text { of } \\
\text { others } \\
\end{array}$ \\
\hline \multirow{6}{*}{ 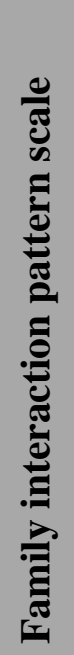 } & Reinforcement & -.083 & $-.322 *$ & $-.314^{*}$ & $-.420 * *$ & $-.558 * *$ & $\begin{array}{c}- \\
.601 * *\end{array}$ \\
\hline & $\begin{array}{l}\text { Social support } \\
\text { system }\end{array}$ & .084 & -.101 & -.220 & $-.299 *$ & $-.526 * *$ & $\begin{array}{c}- \\
.519 * * \\
\end{array}$ \\
\hline & Role & .018 & -.162 & -.115 & $-.291^{*}$ & $-.437 * *$ & $\begin{array}{c}- \\
.491 * * \\
\end{array}$ \\
\hline & Communication & -.002 & -.184 & -.252 & $-.340 * *$ & $-.442 * *$ & $\begin{array}{c}- \\
.535 * * \\
\end{array}$ \\
\hline & Cohesion & .030 & -.131 & $-.268 *$ & -.250 & $-.339 * *$ & $\begin{array}{c}- \\
.405 * *\end{array}$ \\
\hline & Leadership & -.047 & .091 & $-.338 * *$ & $-.286 *$ & $-.341 * *$ & $\begin{array}{c}- \\
.388 * *\end{array}$ \\
\hline
\end{tabular}

*Significant $\mathrm{p}<.05, * *$ Significant $\mathrm{p}<.01$.

Table (1) shows the Correlation among scores of Family interaction pattern Scale and Family burden Scale of the caregivers of patients with alcohol dependent. Significant negative correlation exist between family interaction patterns scales domain reinforcement with disruption of routine family activities, disruption of routine family leisure, disruption of routine family interaction, effect on physical health of others and effect on mental health of others of family burden Scale( $\mathrm{p}<.05 \& \mathrm{p}<$ .01). Significant negative correlation exist between family interaction patterns scales domain social support system, role, and communication with disruption of routine family interaction, effect on physical health of others and effect on mental health of others of family burden Scale $(\mathrm{p}<.05 \& \mathrm{p}<$ .01). Significant negative correlation exist between family interaction patterns scales domain cohesion with disruption of family leisure, effect on physical health of others and effect on mental health of others of family burden Scale $(\mathrm{p}<.01)$. Significant negative correlation exist between family interaction patterns scales domain leadership with disruption of family leisure, disruption of routine family interaction, effect on physical health of others and effect on mental health of others of family burden Scale $(\mathrm{p}<.05 \& \mathrm{p}<.01)$. 
Relationship between Family Interaction pattern, Family Burden and Quality of Life among Caregivers of Patients with Alcohol Dependence

Table-2: Correlation between family burden and quality of life among caregivers of individuals with Alcohol dependence

\begin{tabular}{|c|c|c|c|c|c|}
\hline & \multicolumn{4}{|c|}{ WHO Quality of Life } \\
\hline & & $\begin{array}{c}\text { Physical } \\
\text { health }\end{array}$ & $\begin{array}{l}\text { Psychological } \\
\text { health }\end{array}$ & $\begin{array}{c}\text { Social } \\
\text { relationships }\end{array}$ & Environment \\
\hline \multirow[b]{3}{*}{ 莺 } & Financial burden & $-.255 *$ & -.048 & -.075 & -.075 \\
\hline & $\begin{array}{l}\text { Disruption of routine } \\
\text { family Activities }\end{array}$ & $-.469 * *$ & $-.258 *$ & -.252 & -.319* \\
\hline & $\begin{array}{l}\text { Disruption of family } \\
\text { leisure }\end{array}$ & $-.359 * *$ & $-.271 *$ & -.222 & -.232 \\
\hline \multirow{3}{*}{ 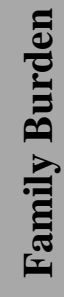 } & $\begin{array}{l}\text { Disruption of family } \\
\text { interaction }\end{array}$ & $-.362 * *$ & $-.367 * *$ & -.229 & $-.343 * *$ \\
\hline & $\begin{array}{l}\text { Effect on physical health } \\
\text { of others }\end{array}$ & $-.277^{*}$ & $-.446 * *$ & $-.353 * *$ & $-.376 * *$ \\
\hline & $\begin{array}{l}\text { Effect on mental health } \\
\text { of others }\end{array}$ & $-.368 * *$ & $-.503 * *$ & $-.383 * *$ & $-.406 * *$ \\
\hline
\end{tabular}

*Significant $\mathrm{p}<.05, * *$ Significant $\mathrm{p}<.01$.

Table (2) shows the Correlation among Family burden Scale, and WHO QOL of caregivers of patients with alcohol dependent. This indicates that significant negative correlation exist between financial burden Scale domain financial burden with physical health of WHO QOL scale $(\mathrm{p}<$ .05). Significant negative correlation exist between financial burden Scale domain disruption of routine family activities and disruption of routine family interaction with physical health, psychological health and environment of WHO QOL scale $(\mathrm{p}<.05 \& \mathrm{p}<.01)$. Significant negative correlation exist between financial burden Scale domain disruption of family leisure with physical health, psychological health of WHO QOL scale $(\mathrm{p}<.05 \& \mathrm{p}<.01)$. Significant negative correlation exist between financial burden Scale domain effect on physical health of others and effect on mental health of others with physical health and social relationship of WHO QOL scale $(\mathrm{p}<.05 \& \mathrm{p}<.01)$.

Table-3: Correlation between quality of life and family interaction pattern among caregivers of individuals with alcohol dependence

\begin{tabular}{|c|c|c|c|c|c|}
\hline & \multicolumn{4}{|c|}{ WHO Quality of Life } \\
\hline & & $\begin{array}{l}\text { Physical } \\
\text { health }\end{array}$ & $\begin{array}{l}\text { Psychological } \\
\text { health }\end{array}$ & $\begin{array}{l}\text { Social } \\
\text { relationships }\end{array}$ & Environment \\
\hline \multirow{6}{*}{ 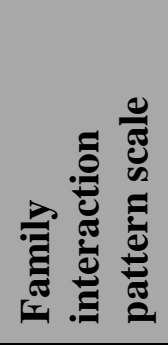 } & Reinforcement & $.361 * *$ & $.460 * *$ & $.484^{* *}$ & $.455 * *$ \\
\hline & $\begin{array}{ll}\begin{array}{l}\text { Social } \\
\text { system }\end{array} & \text { support } \\
\end{array}$ & .075 & $.374 * *$ & $.329 *$ & $.343 * *$ \\
\hline & Role & .022 & $.279 *$ & $.275^{*}$ & $.405^{* *}$ \\
\hline & Communication & .061 & $.314^{*}$ & $.291 *$ & $.379 * *$ \\
\hline & Cohesion & .211 & $.349 * *$ & $.257^{*}$ & $.330 * *$ \\
\hline & Leadership & .004 & .232 & .217 & $.301^{*}$ \\
\hline
\end{tabular}

*Significant $\mathrm{p}<.05, * *$ Significant $\mathrm{p}<.01$. 
Table (3) shows the Correlation among scores of Family Interaction Pattern Scale and WHO QOL of the caregivers of patients with alcohol dependent. Significant positive correlation exists between domains of Family Interaction Pattern Scale (i.e. reinforcement with physical health, psychological health, social relationship and environment of WHO QOL scale $(\mathrm{p}<.01)$. Significant positive correlation exists between domains of Family Interaction Pattern Scale (i.e. social support system, role, communication and cohesion with psychological health, social relationship and environment of WHO QOL scale $(\mathrm{p}<.05 \& \mathrm{p}<.01)$. Significant positive correlation exists between domain leadership domain of Family Interaction Pattern Scale and environment domain of WHO QOL scale $(\mathrm{p}<.05)$.

\section{DISCUSSION}

\section{Discussion of methodology:}

The aim of the study was to assess the relationship between family interaction pattern, family burden schedule and Quality of life in the caregivers of individuals with alcohol dependence. This study was conducted at the Ranchi Institute of Neuro-Psychiatry and Allied Sciences, Ranchi. It was a cross sectional study and purposive sampling was used. The present study consisted of 60 caregivers of individuals with alcohol dependence, those who were willing to participate in the study and those who have satisfied with inclusion and exclusion criteria have been included in the study. The socio demographic data sheet had been used for collecting socio demographic details of the caregivers of individuals with alcohol dependence. To assess the alcohol severity of the patient, the alcohol severity index scale was applied. Family interaction pattern scale, family burden interview schedule and WHO Quality of life scale were applied on the caregivers of individuals with alcohol dependence.

\section{Relationship between family interaction pattern, family burden and quality of life in caregivers of patients with_alcohol dependent:}

Reinforcement shows its negative correlation with disruption of routine family activities, disruption of routine family leisure, disruption of routine family interaction, effect on physical health of others and effect on mental health of others of caregivers of patients with alcohol dependent. Social support system, role, and communication shows its negative correlation with disruption of routine family interaction, effect on physical health of others and effect on mental health of others. Cohesion shows its negative correlation with disruption of family leisure, effect on physical health of others and effect on mental health of others. Cohesion in any family determines the boundary alignment and could affect the emotional distance among subsystem in family that would ultimately result in poor cohesiveness and poor family functioning (Epstein et al, 1978). Leadership shows its negative correlation with disruption of family leisure, disruption of routine family interaction, effect on physical health of others and effect on mental health of others. 


\section{Relationship between Family Interaction pattern, Family Burden and Quality of Life among Caregivers of Patients with Alcohol Dependence}

The current study result matches with the previous study done by Paparrigopoulos (2009) alcohol dependence may have a considerable impact on family interaction as shown by the high scores of burden and mild psychopathology recorded in the caregivers. Financial burden shows its negative correlation with physical health of quality of life of caregivers of patients with alcohol dependent. Quality of life reflects the health, happiness, life satisfaction and well-being and it influence to external and internal environment. Burden creates stress which results while caring any family member from chronic illness. Disruption of routine family activities and Disruption of routine family interaction shows its negative correlation with physical health, psychological health and environment of quality of life of caregivers of patients with alcohol dependent. Disruption of routine family leisure shows its negative correlation with physical health, psychological health of quality of life of caregivers of patients with alcohol dependent. Effect on physical health of others, and Effect on mental health of others shows its negative correlation with psychological health, social relationship and environment of quality of life of caregivers of patients with alcohol dependent. Theories of family system emphasize mutual relationship among functions of family, and domain affects the whole system (Bowen, 1960); therefore, the findings of the present study highlight a natural interdependence of family interaction, family burden and quality of life among caregivers of Patient with alcohol dependent. Among the individual family interaction pattern variables, reinforcement shows positive association with good physical health, psychological health, social relationship and environment of quality of life. Likewise social support system, role, communication and cohesion shows positive association with psychological health, social relationship and environment of quality of life. It is evident that family function regulates the flow of uninterested communication and the merit of communication lies in quality of expressiveness. The same thing applies to other functions like social support (Epstein et al., 1978) and reinforcement as well. Independence is also the quality that requires the support of role structuring, communication and quality of family interaction (Epstein et al., 1978). The current study shows significant positive correlation between the domains of effect on physical health of others and effect on mental health of others of Family burden Scale, with physical health of WHO QOL of the caregivers of patients with alcohol dependent. It can be explained that Caregiver burden is usually defined as multidimensional response to the negative appraisal and perceived strain which results from taking care of an ill person. It improvises the physical, psychological, emotional and functional health of caregivers (Parks \& Novielli, 2000 \& Carretero, 2009).

\section{CONCLUSION:}

This study found the significant positive correlation among family interaction pattern, Family burden and quality of life. Though small sample size was the major limitation of the study yet it offers useful implications in planning psychiatric social work interventions to improve the quality of life of caregivers while providing psycho social care to individual with alcohol dependence. The need of education, advice, information, counseling, motivation are essential for most of the care givers of individual with alcohol dependence having higher level of intensity of 


\section{Relationship between Family Interaction pattern, Family Burden and Quality of Life among Caregivers of Patients with Alcohol Dependence}

burden. If appropriate precautions are not taken in time, the care giver's stress level will go high and there may be a real danger to the both physical and mental health of the care givers that they may suffer from any illness very soon. Various tips are given to the care givers to balance their critically important care giving role with their own health and wellbeing. Emphasis should be laid on prevention, early diagnosis and prompt treatment for alcohol dependence. Communities should be educated about the consequences of alcohol dependence in terms of physical, social and family issues. Clinicians should also pay attention to the needs of caregivers of patients with alcohol dependence.

\section{REFERENCES}

Bowen, M. (1976). Theory in the practice of psychotherapy. In P. J. Guerin. (Ed.). Family therapy. New York: Gardne

Carretero S., Garces J., Rodenas F. \& Sanjose V. (2009). The informal caregiver's burden of dependent people: theory and empirical review. Archives of Gerontology and Geriatrics 49(1), 74-79

Clark DB, Moss HB, Kirisci L, et al. (1995). Psychopathology in preadolescent sons of fathers with substance use disorders. J Am Acad Child Adolesc Psychiatry, 36(4) : 495- 502.

Conlin MM. (1995). Silent suffering: a case study of elder abuse and neglect. Journal of the American Geriatrics Society. 43:1303-1308.

Cooney C, Howard R. (1995). Abuse of patients with dementia by carers. International Journal of Geriatric Psychiatry. 10:735-741.

Epstein NB, Bishop DS, Levin S. (1978).The Mc Master model of family Functioning: a review of the normal family. In: Walsh, F (Ed). Normal Family Process. New York: Guild Ford.

Panda SK, Lokabhiramam MS, Jayashree, et al. (2005). Risk Factors for HIV Infection in Injection Drug Users and Evidence for Onward Transmission of HIV to Their Sexual Partners in Chennai, India. JAIDS, 39(1): 9-15.

Paparrigopoulos. (2009). Family burden in alcohol Dependence University of Athens, Medical School, Eginition Hospital, Athens, Greece. European Journal of Epilepsy, 24-449.

Parks S.M. \& Novielli K.D. (2000). A practical guide to caring for caregivers. American Family Physician 62(12), 2613-2622.

Shankardass MK, Ranganathan S, Benegal V, et al. (2001). 'Burden on Women due to Drug Abuse by Family Members'. Report submitted to Ministry of Social Justice and Empowerment and UNDCP, ROSA.

Shyangwa, P.M., Tripathi, B.M., \& Lal, R. (2009). Family burden in opioid dependence syndrome in tertiary care centre. Journal of Nepal Medical Association, 47, 113-9. 